\title{
Risk factors for bronchial hyperresponsiveness in workers exposed to acid anhydrides
}

\author{
R.D. Barker*, M.J.A. van Tongeren**, J.M. Harris*, K. Gardiner**, \\ K.M. Venables*, A.J. Newman Taylor*
}

Risk factors for bronchial hyperresponsiveness in workers exposed to acid anhydrides. R.D. Barker, M.J.A. van Tongeren, J.M. Harris, K. Gardiner, K.M. Venables, A.J. Newman Taylor. (C) ERS Journals Ltd 2000.

ABSTRACT: Risk factors for bronchial hyperresponsiveness have previously been established in the general community. In settings where occupational asthma is a risk, it has not been established whether occupational sensitization or measures of exposure are important.

Bronchial responsiveness to histamine was measured in a cohort of 506 workers exposed to acid anhydrides. Skin-prick tests were performed with conjugates of phthalic, maleic and trimellitic anhydride with human serum albumin and with common inhalant allergens. Employment and smoking histories were recorded. Occupational exposure was measured using personal air samplers and estimates of past exposure made by retrospective exposure assessment.

Three hundred and seventy workers $(73 \%)$ had bronchial responsiveness measured (median age 39 yrs, range 18-77) and $46(12 \%)$ of these were hyperresponsive (provocative dose causing a $20 \%$ fall in forced expiratory volume in one second (FEV1; PD20) $\leq 8 \mu \mathrm{mol})$. Twelve $(3 \%)$ of these responsive workers had a skin-prick test reaction to an acid anhydride conjugate, $124(34 \%)$ to a common inhalant allergen, and $148(40 \%)$ were current smokers. Multivariate analysis showed that occupational sensitization, sensitization to a common inhalant allergen, age, and pack-years of smoking were independent risk factors for bronchial hyperresponsiveness. Of these only occupational sensitization was completely independent of baseline FEV1.

It is concluded that sensitization to acid anhydrides is a significant risk factor for bronchial hyperresponsiveness. However, measures of personal acid anhydride exposure were not associated with bronchial hyperresponsiveness. Eur Respir J 2000; 15: 710-715.

In the UK occupational asthma is the most frequently reported work related respiratory disease [1] and may account for $2-6 \%$ of asthma in adults [2]. Laboratory based studies have shown that nonspecific bronchial hyperresponsiveness (BHR) is a common accompaniment to occupational asthma and that BHR may worsen with exposure to the relevant sensitizer [3]. Bronchial responsiveness is routinely measured as part of the laboratory diagnosis of occupational asthma and is used increasingly in surveys of asthma among working populations. Studies conducted in the general community suggest that atopy, cigarette smoking, age and baseline airway calibre are important risk factors for BHR [4-7] and that allergens encountered indoors are of particular relevance [8]. To date, however, few studies of working populations have assessed the influence of immediate skin-prick test reactivity, to an occupational sensitizer on bronchial responsiveness, whilst taking into account these other confounders [9].

Acid anhydrides (AA) are reactive, low molecular weight chemicals, with uses that include the manufacture of alkyd and epoxy resins. Inhalation of these chemicals may cause asthma that is frequently associated with specific immunoglobulin (Ig)E directed at conjugates of acid anhy-
*Dept of Occupational and Environmental Medicine, National Heart and Lung Institute, Imperial College of Science, Technology and Medicine, London, UK. **Institute of Occupational Health, University of Birmingham, Birmingham, UK.

Correspondence: R.D. Barker

King's College Hospital

Bessemer Road

Camberwell

London

UK

Fax: 442073463589

Keywords: Anhydrides bronchial hyperreactivity occupational diseases

Received: April 61999

Accepted after revision January 232000

Funded by the Health and Safety Executive of the UK and The Royal Society. drides with human serum albumin (HSA) [10]. The risk of sensitization may be related to exposure, cigarette smoking and major histocompatibility complex class II antigens $[11,12]$.

The authors have studied an historical cohort of workers exposed to phthalic (PA), maleic (MA) and trimellitic anhydride (TMA). The relationship between full-shift exposure to AA and sensitization in these workers is the subject of another paper [13]. In the present study, the relationship between sensitization and BHR was examined. A possible relationship between BHR and two measures of exposure to AA was also investigated.

\section{Methods}

\section{Design}

This was a retrospective cohort study.

\section{Population}

Four industrial sites that used AA were identified. Three of the sites manufactured alkyd resins, a constituent of paints and varnishes; the fourth made cushioned flooring. 
The alkyd resin plants used principally PA but also MA and TMA. These chemicals were added to oils and alcohols in large reactor vessels. The AA could be loaded manually as powders, or automatically in the case of liquid PA. Opportunities for exposure occurred during loading of AA into the reactors, testing and filtering the resin, and during maintenance work. The three sites had been producing alkyd resins with AA since before 1950. Adequate personnel records were available since 1960 at two sites and since 1979 at the third. For this reason the cohort inception was January 11960 at two of the alkyd resin plants and January 11979 at the third.

The fourth site had used TMA in the manufacture of cushioned flooring since 1979. TMA powder was mixed with polyvinyl chloride (PVC) copolymer and solvent to make a "masterbatch". To this, pigment was added and the resulting ink was placed into large heated troughs. Into the six troughs were dipped patterned rotogravures which transferred ink onto the flooring. The flooring was passed through an oven with resultant expansion of a foam layer. At points where TMA containing ink had been applied, foam expansion was inhibited, producing a grooved or "debossed" effect. The highest TMA exposures were in the "masterbatch" preparation area but airborne TMA was detectable throughout the plant [14]. The inception date for the cohort at this site was January 11979.

The cohort included everyone who had worked in an area of AA use, at any of the four sites, for at least 1 month, and had started employment after the cohort inception and before January 1 1992. It therefore included, those currently employed in an area of AA use, those who had transferred to other areas within the company, and those who had left the company completely.

\section{Bronchial hyperresponsiveness}

Bronchial responsiveness was measured using the rapid method described by YAN et al. [15]. Forced expiratory volume in one second (FEV1) and forced vital capacity were measured with calibrated, leak free, Vitalograph dry-wedge spirometers (Vitalograph Ltd. Buckingham, Buckinghamshire, UK). Trained observers supervised the tests, aiming for at least two technically satisfactory traces that were within $5 \%$ or $100 \mathrm{~mL}$ of each other, whichever was greater. Following inhalation of isotonic saline, subjects with a history of asthma or whose FEV1 was $<1.5$ $\mathrm{L}$ took one inhalation of $3.1 \mathrm{mg} \cdot \mathrm{mL}^{-1}$ histamine $(0.029$ $\mu \mathrm{mol})$. The cumulative dose of histamine was doubled with each subsequent set of inhalations. The challenge was stopped when the FEV1 fell by $>20 \%$ from the postsaline value, when the maximum dose of $3.9 \mu \mathrm{mol}$ was reached or when the subject asked for the test to discontinue. If subjects had no history of asthma and their baseline FEV1 was $\geq 1.5$ litres, the test was started with two puffs of $3.1 \mathrm{mg} \cdot \mathrm{mL}^{-1}$ histamine and quadrupling doses of histamine were administered until the FEV1 fell by $10-20 \%$ from the baseline value at which point the protocol changed to doubling doses. Subjects were excluded if their baseline FEV1 was $<1$ litre. The provocative dose of histamine causing a $20 \%$ fall in FEV1 (PD20) was estimated by linear interpolation of the last two points on the dose-response curve. Extrapolation to $8 \mu \mathrm{mol}$ of histamine was allowed. BHR was defined as a PD20 of $\leq 8$ $\mu \mathrm{mol}$ of histamine.

\section{Skin-prick tests}

Skin prick tests were performed on the anterior surface of the right forearm and were read after $10 \mathrm{~min}$. The largest inner diameter of each skin wheal was recorded, along with the diameter perpendicular to this. The mean of these two measurements was taken as the weal size provoked by that allergen. Each measurement was checked by a second reader. Recordings were made without knowledge of the bronchial responsiveness. Skin-prick tests were undertaken with cat fur, mixed grass pollen, Dermatophagoides pteronyssinus (Bencard, Brentford, Greater London, UK), PAHSA [16], TMA-HSA, MA-HSA, with histamine and HSA controls. Sensitization to AA was defined as a skin wheal $\geq 3 \mathrm{~mm}$ provoked by PA-HSA, MA-HSA or TMAHSA after subtraction of the HSA control. Atopy was defined as an immediate skin-prick test reaction of $\geq 3$ $\mathrm{mm}$ provoked by cat fur, mixed grass pollen or D. pteronyssinus.

\section{Smoking and work experience}

Subjects answered self-administered questionnaires relating to smoking habits and work experience. A current smoker was defined as someone who answered "yes" to "Do you smoke?". Exsmokers answered "no" to this question and "yes" to "Have you ever smoked as much as one cigarette a day or one cigar a week, or $28 \mathrm{~g}$ of tobacco a month, for as long as a year?". Never smokers answered "no" to both of these questions. Cumulative tobacco consumption was calculated in pack-years using the subjects' self-reported average consumption over 5-yr periods extending back to 1960 . Where a smoking history began before 1960 the average consumption for the first 5-yr period was extrapolated back to the date of starting to smoke.

\section{Exposure to acid anhydrides}

Measurements of airborne AA were made over full shifts in 1992-1993 [13]. The measurements were made during planned factory visits that lasted 2-4 weeks. Allocation of monitoring equipment to workers within each "job title" was performed using a random number programme to select both the worker and the shift. The occupational hygienist aimed to obtain full shift samples from $\sim 1$ in every 10 shifts worked during the hygienist's visits to the sites in order to estimate the average exposure to AA experienced in each "job title". One hundred and thirty measurements of full shift AA exposure were made (range 1-16 per "job title"). Sampling and analysis was performed according to standard methods [17]. Changes in work practice that took place after the inception date for the cohort were recorded following consultation with process workers, management, engineers and occupational hygienists at the sites [18]. A panel of three academic occupational hygienists used knowledge of these changes in production, as well as pre-existing exposure measurements made by the companies, to generate a job-timeexposure matrix for each AA and each site. This process has been described fully elsewhere [18]. The duration spent by each individual in each job-time-exposure period was calculated and summed to obtain an estimate of cumulative exposure to AA. The result was expressed in micrograms per cubic metre-years. To obtain the highest 
full shift exposure for each worker, their job associated with the highest full shift exposure to AA was identified. The estimated exposure in this job title was allocated to the individual [13].

\section{Statistical analysis}

For descriptive purposes the subjects were divided into four age groups $(<30,30-<40,40-<50, \geq 50 \mathrm{yrs})$, each containing approximately equal numbers. Individuals were also separated into three groups according to their highest full shift exposure to AA $\left(<10,10-100,>100 \mu \mathrm{g} \cdot \mathrm{m}^{-3}\right)$. Univariate comparisons and correlations were performed using appropriate parametric and nonparametric methods. Fisher's exact test was used for tests of proportions with other analyses completed using logistic regression models. Model building took a forward stepwise approach, variables being added to the model if the likelihood ratio statistic for their inclusion was associated with a probability of $<0.05$. Cumulative exposure to AA was $\log _{10}$ transformed to produce an approximately Normal distribution. SAS (SAS Institute Inc., Cary, NC, USA) and Stata (Stata Corporation, College Station, Texas, USA) statistical software were used. The study was approved by the ethics committee of the Royal Brompton Hospital, London, UK.

\section{Results}

Five hundred and six workers met the cohort definition. Twenty-six had died, 35 refused to take part and 44 could not be traced. No data are available for these workers. Of the remaining 401, eight did not have a histamine challenge because of angina pectoris and a meeting could not be arranged for a further 23. Data for 11 subjects were incomplete so $359(71 \%)$ had sufficient information for the multivariate analyses.

A description of the population is shown in table 1 . The prevalence of BHR and major risk factors for BHR are shown, by age group, in fig. 1. The prevalence of BHR and current, or exsmoking increased with age whilst the prevalence of atopy fell with age.

Table 1. - Demographic details of 359 acid anhydride exposed workers

\begin{tabular}{ll}
\hline Age & $39(18-77)$ \\
BHR & $46(12)$ \\
Males & $348(97)$ \\
Exposed to AA at the time of & $163(45)$ \\
$\quad$ medical assessment & $124(34)$ \\
Atopic & $12(3)$ \\
Positive AA -HSA skin-prick test & $148(40)$ \\
Current smoker & $216(60)$ \\
Ex- or never smoker & $7.5(0-102)$ \\
Pack-years of cigarettes & $54.7(0-17545)$ \\
Cumulative AA exposure & \\
Highest full shift AA exposure & \\
low $<10$ & $196(53)$ \\
medium $10-100$ & $121(33)$ \\
high $>100$ & $53(14)$ \\
\hline
\end{tabular}

Number of subjects are given as absolute numbers with the percentage in parentheses, or as median with range in parentheses. BHR: bronchial hyperresponsiveness; AA: acid anhydride; HSA: human serum albumin. ${ }^{\#}$ : values expressed as micrograms per cubic metre-years; ${ }^{+}:$values expressed as micrograms per cubic metre.

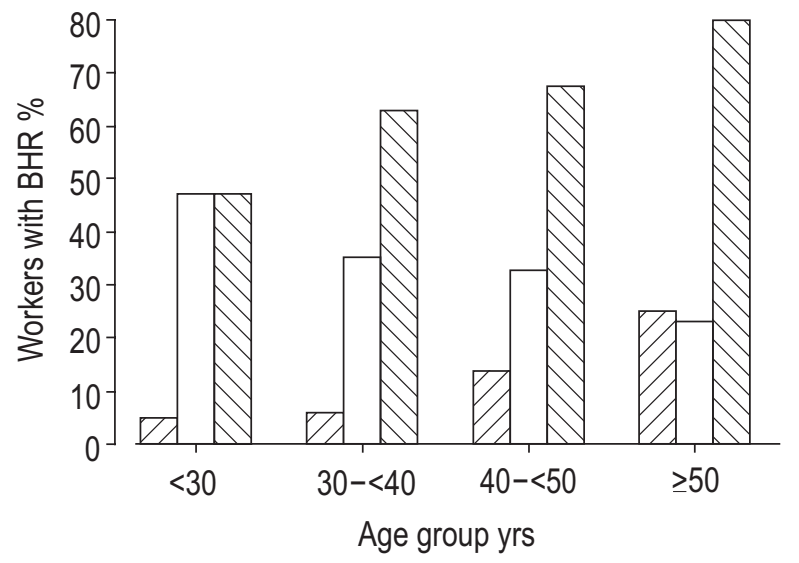

Fig. 1. - The proportion of workers with bronchial hyperresponsiveness (BHR; $\mathbb{Z})$, atopy $(\square)$ and current or exsmokers $(\mathbb{\mathbb { Q }})$ in each age group.

Univariate analyses showed that those with BHR were more likely to have an immediate skin test reaction to AAHSA and had higher cumulative exposure to AA (table 2). Five of $12(42 \%)$ workers with an immediate skin test reaction to AA-HSA had BHR compared with 39 of 350 $(11 \%)$ without evidence of sensitization $(p=0.01)$. Workers with BHR had smoked more and had lower baseline lung function than those without BHR. A greater proportion of those with BHR were atopic and were current smokers although these associations were not statistically significant in univariate analyses. The prevalence of BHR increased in a linear fashion across the four age groups (fig. 1). Graphic display of the data shows that among those under the age of $40 \mathrm{yrs}$, BHR occurred predominantly in those who were atopic. The prevalence of atopy fell with age, and among those aged $>40$ yrs. BHR occurred principally in nonatopic smokers or exsmokers (fig. 2).

Table 2. - Univariate analyses of the determinants of bronchial hyperresponsiveness

\begin{tabular}{|c|c|c|c|}
\hline & $\begin{array}{l}\text { PD20 } \\
\leq 8 \mu \mathrm{mol}\end{array}$ & $\begin{array}{l}\text { PD20 } \\
>8 \mu \mathrm{mol}\end{array}$ & p-value \\
\hline $\mathrm{n}$ & 46 & 324 & \\
\hline $\begin{array}{l}\text { Immediate skin-prick test } \\
\text { reaction to AA-HSA }\end{array}$ & $5(11)$ & 7 (2) & 0.01 \\
\hline Current smoking & $22(48)$ & $126(39)$ & 0.26 \\
\hline Atopy & $19(43)$ & $105(33)$ & 0.24 \\
\hline $\begin{array}{l}\log _{10} \text { cumulative AA } \\
\text { Exposure* }\end{array}$ & $2.0 \pm 1.0$ & $1.7 \pm 0.8$ & 0.03 \\
\hline \multicolumn{4}{|l|}{$\begin{array}{l}\text { Maximum full shift } \\
\text { exposure to } \mathrm{AA}^{\#}\end{array}$} \\
\hline low $<10$ & $17(37)$ & $179(55)$ & \\
\hline medium $10-100$ & $20(43)$ & $101(31)$ & \\
\hline high $>100$ & $9(20)$ & 44 (14) & 0.03 \\
\hline Age & $49 \pm 14.5$ & $40 \pm 11.8$ & 0.001 \\
\hline Pack-yrs of tobacco smoking & $19.8 \pm 20.9$ & $9.9 \pm 12.6$ & 0.003 \\
\hline $\mathrm{FEV}_{1}^{+}$ & $3.0 \pm 0.8$ & $3.9 \pm 0.8$ & $<0.001$ \\
\hline
\end{tabular}

Data are presented as absolute numbers with the percentage in parentheses, or mean \pm SD. PD20: provocative dose of histamine causing a $20 \%$ fall in forced expiratory volume in one second (FEV1); AA: acid anhydride; HSA: human serum albumin. *: values expressed in micrograms per cubic metre-years; ${ }^{\#}$ : values expressed in micrograms per cubic metre; ${ }^{+}$: values expressed in litres. 


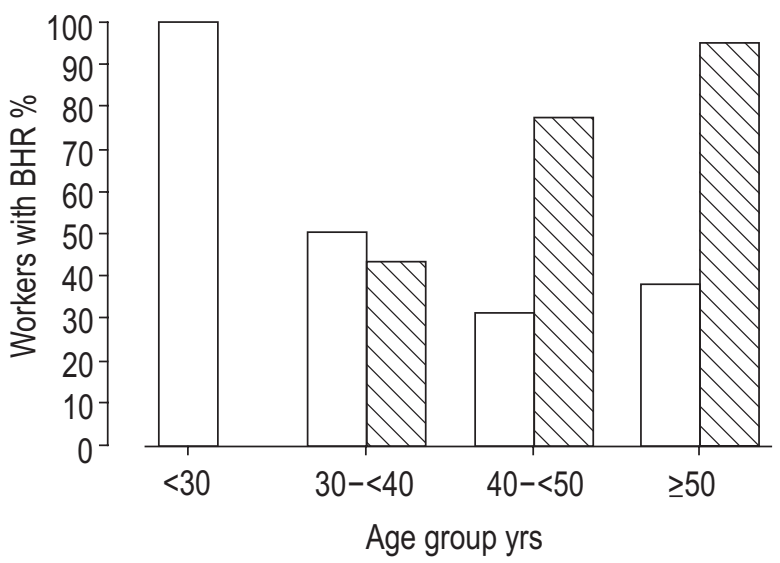

Fig. 2. - The proportion of workers with bronchial hyperresponsiveness (BHR), who were atopic $(\square)$ or current or exsmokers $(\mathbb{\Xi})$ in each age group.

There were important associations between the variables. Older persons were more likely to have a higher cumulative exposure to AA $(\mathrm{p}<0.001)$ and higher levels of cumulative smoking $(\mathrm{p}<0.001)$. Increased cumulative smoking was also associated with reduced FEV1 $(\mathrm{p}<0.001)$ and increased cumulative exposure to AA $(\mathrm{p}=0.03)$. There was no evidence to suggest that maximum exposure to AA was associated with either age $(\mathrm{p}=0.65)$ or FEV1 $(\mathrm{p}=0.23)$.

To assess whether the relationships shown in univariate analyses were independent of one another, multivariate logistic regression was performed. The first analysis excluded FEV1 as FEV1 was associated with both age $(\mathrm{p}<0.001)$ and pack-years of tobacco smoking $(\mathrm{p}<0.001)$ and may lie on the causal pathway between these two factors and BHR. This multivariate analysis therefore included sensitization to $\mathrm{AA}, \log _{10}$ cumulative AA exposure, age, atopy, pack-years and current smoking status (table 3 ). It revealed that an immediate skin test reaction to AAHSA, age, atopy and pack-years of tobacco smoking were significantly and independently related to BHR. The odds ratio (OR) of BHR was nearly four times higher in those with an immediate skin test reaction to AA-HSA compared to those without. In addition, the prevalence of BHR increased by $\sim 5 \%$ per year of age and by $2 \%$ for

Table 3. - Multivariate analysis of the determinants of bronchial hyperresponsiveness (BHR)

\begin{tabular}{lcc}
\hline Independent variable & OR 95\% CI & p-value \\
\hline Age & 1.05 & $<0.001$ \\
Immediate skin test reaction & $(1.02-1.08)$ & \\
$\quad$ to AA-HSA & 3.89 & 0.05 \\
Atopy & $(1.03-14.72)$ & \\
Pack-yrs tobacco smoking & 2.12 & 0.04 \\
& $(1.03-4.34)$ & \\
& $(1.02$ & 0.05 \\
\hline
\end{tabular}

BHR was defined as a provocative dose of histamine causing a $20 \%$ fall in forced expiratory volume in one second of $8 \mu \mathrm{mol}$. The number of subjects was 359 . $\log _{10}$ cumulative acid anhydride exposure, highest full shift exposure and current smoking were not independent predictors of BHR. 95\% CI: 95\% confidence interval; OR: odds ratio; AA: acid anhydride; HSA: human serum albumin. each pack-year. After adjusting for these effects, cumulative exposure to AA and current smoking were not independent predictors of BHR. The OR for age, atopy and cumulative smoking were not significantly modified when the workers with an immediate skin-prick test reaction to AA HSA conjugates were excluded from the analysis.

Finally, the independence of these risk factors for BHR from baseline FEV1 was assessed (table 4). BHR was strongly associated with FEV1, the risk of BHR increasing five-fold with every litre decrease in FEV1. After taking account of this relationship, an immediate skin test reaction to AA-HSA was the only other independent predictor of BHR $(\mathrm{OR}=4.90,95 \%$ confidence interval $(95 \%$ CI $) 1.24,19.37)$. The associations of atopy, age and pack-years of cigarette smoking with BHR were not significant after adjustment for baseline FEV1.

\section{Discussion}

This study showed that sensitization to AA was associated with BHR. There was no additional effect of cumulative exposure to AA or highest full shift exposure to AA. Atopy, measured as an immediate skin test reaction to common inhalant allergens, and pack-years of tobacco smoking were associated with BHR, although current smoking was not. The most powerful risk factor for BHR was baseline lung function. After taking account of FEV1 the relationships of smoking, age and atopy with BHR were not significant.

Data from clinical studies suggest that many subjects with AA induced asthma, have specific IgE directed against AA-HSA [19-22]. Associations between specific $\mathrm{IgE}$ and work related respiratory symptoms or BHR have been more difficult to show in workplace based studies. This may be because affected workers have left the site by the time the survey is completed [11] or because a low threshold for defining an IgE response was chosen [23, 24]. The current authors believe that the present report is the first to show an epidemiological association of an immediate skin test reaction to AA with BHR.

BHR among those developing occupational asthma does not appear to antedate exposure to the relevant allergen or hapten. It has been shown to follow, rather than precede, exposure among workers developing asthma in lumberyards, research laboratories and in aluminium pot rooms

Table 4. - Multivariate analysis of the determinants of bronchial hyperresponsiveness (BHR)

\begin{tabular}{lcc}
\hline Independent variable & OR $(95 \% \mathrm{CI})$ & $\mathrm{p}$-value \\
\hline FEV1 & 0.21 & $<0.001$ \\
$\begin{array}{l}\text { Immediate skin test reaction } \\
\text { to AA-HSA }\end{array}$ & $\begin{array}{c}(0.13-0.35) \\
(1.49-20.76)\end{array}$ & 0.01 \\
\hline
\end{tabular}

BHR was defined as a provocative dose of histamine causing a $20 \%$ fall in forced expiratory volume in one second (FEV1) of 8 $\mu$ mol. The number of subjects was 359. With FEV1 included in the model building age, pack-yrs tobacco smoking, current smoking, $\log _{10}$ cumulative acid anhydride (AA) exposure, highest full shift exposure and current smoking were not independent predictors of BHR. 95\% CI: 95\% confidence interval; OR: odds ratio; AA: acid anhydride; HSA: human serum albumin. 
[25]. Furthermore, exposure to allergen is known to worsen BHR [3, 26] and improvement in BHR may occur following cessation of exposure [27]. In the current study, although the confidence intervals were large, those with an immediate skin-prick test reaction of $3 \mathrm{~mm}$ to an AAHSA conjugate, were associated with a four times higher prevalence (OR 3.89, 95\% CI 1.03-14.73) of BHR. This is a large OR suggesting that sensitization by this chemical has a strong impact on BHR in exposed workers.

In a multivariate analysis there was no relationship between cumulative exposure to AA and BHR. Although a relationship was suspected from the univariate analysis, it was confounded by age and pack-years of cigarette smoking. Some agents, such as cigarettes, do appear to have a cumulative impact on BHR. The lack of a relationship for respiratory sensitizers such as AA may be because those who develop symptoms tend to move out of highly exposed jobs. In support of this, a study of occupational asthma among salmon processors showed an inverse relationship between the risk of having occupational asthma and duration of exposure [28]. A relationship between cumulative exposure to AA and BHR cannot be completely excluded because there is bound to be misclassification of exposure in a study looking back over 30 yrs and misclassification would weaken any association [17].

The authors have previously shown that AA exposure induced sensitization in a dose related manner [13]. In the present study the authors have not been able to demonstrate that either cumulative exposure or highest full shift exposure to AA impact on BHR independently of sensitization.

Nearly all community based studies of adults show an association of atopy with BHR. Where it has been assessed this relationship appears to be independent of baseline airway calibre $[5,7,29]$. The current study shows a relationship between atopy and BHR in a multivariate analysis that was not apparent in univariate analysis. Figure 2 shows that this is probably due to confounding by age, with BHR being predominantly associated with atopy in younger subjects and smoking in older subjects. This emphasizes the importance of multivariate analyses when associations of BHR are being investigated in populations with a wide age range.

The authors have previously shown that there were more atopic individuals among those who were sensitized to AA (AA-HSA skin prick test 7/12 (58\%), negative AA-skinprick test $117 / 350(33 \% ; p=0.074))[13]$. This may, in part, explain why a positive skin-prick test directed against AA-HSA but not atopy appeared in the multivariate models of predictors of BHR. The OR for the relationship between atopy and BHR in a model that adjusted for baseline FEV1 was 1.82 (95\% CI 0.86-3.84). This OR is similar in magnitude to that seen in the larger study of BRITTON et al. [5]. It suggests that the association of sensitization to common inhalant allergens with BHR is real and largely independent of airway calibre, even though the elevated OR was not statistically significant in the present study.

Several studies suggest that the prevalence of BHR decreases with age from the late teens into the forties before increasing again in later life $[4,5]$. More recently the increased risk of BHR largely has been shown to be, largely, attributable to age related changes in baseline airway calibre [5-7]. Two of these studies suggest that the risk of BHR actually falls with age once baseline lung function has been accounted for $[5,6]$. The present study confirms the increased risk of BHR with age. The fact that this relationship is lost after adjusting for baseline FEV1 suggests that it is mainly due to age related changes in the geometry of the airways.

Short term exposures to cigarette smoke produce inconsistent changes in bronchial responsiveness in humans [30]. Most large epidemiological studies including a wide age range of subjects show an association of smoking with BHR [4-7, 29]. There is some evidence to suggest that older smokers are at particular risk [4]. When multivariate analyses are performed, the association of BHR with smoking is usually lost after adjustment for baseline FEV1 [5-7, 29]. The present study suggests that BHR is a consequence of chronic rather than acute cigarette exposure. Like age, it appears to act as a risk factor, through its impact on baseline airway calibre. In a multivariate model, with relevant confounders, pack-years of cigarette smoking was significantly associated with BHR but current cigarette smoking was not.

In conclusion, a relationship between sensitization to acid anhydrides and bronchial hyperresponsiveness has been shown. The influence of age and cigarette smoking is probably through changes in baseline airway calibre. Studies of bronchial hyperresponsiveness in occupational groups should take into account confounding by known risk factors.

Acknowledgements. The authors thank A. Robertson, J. King, M. Cunningham Hill and F. Rose for advice and assistance. In addition the authors thank the management and employees of the plants for their cooperation and hospitality, R. Tee and J. Welch for the immunological work, N. Murthy and S. Wijayawickrama for analyzing the air samples, M. Nieuwenhuijsen for assistance with exposure assessments and D. Gompertz for his unfailing encouragement. Finally the authors thank all of the department members for assistance with field work.

\section{References}

1. Ross DJ, Sallie BA, McDonald JC. SWORD '94: surveillance of work-related and occupational respiratory disease in the UK. Occup Med 1995; 45: 175-178.

2. Meredith S, Nordman H. Occupational asthma: measures of frequency from four countries. Thorax 1996; 51: 435440.

3. Durham SR, Graneek BJ, Hawkins R, Newman Taylor AJ. The temporal relationship between increases in airway responsiveness to histamine and late asthmatic responses induced by occupational agents. J Allergy Clin Immunol 1987; 79: 398-406.

4. Burney PGJ, Britton JR, Chinn S, et al. Descriptive epidemiology of bronchial reactivity in an adult population: results from a community study. Thorax 1987; 42: 38-44.

5. Britton J, Pavord I, Richards K, et al. Factors influencing the occurrence of airway hyperreactivity in the general population: the importance of atopy and airway calibre. Eur Resp J 1994; 7: 881-887.

6. Bakke PS, Baste V, Gulsvik A. Bronchial responsiveness in a Norwegian community. Am Rev Respir Dis 1991; 143: 317-322. 
7. Rijcken B, Schouten JP, Mensinga TT, Weiss ST, De Vries K, van der Lende R. Factors associated with bronchial hyperresponsiveness to histamine in a population sample of adults. Am Rev Respir Dis 1993; 147: 14471453.

8. Sears MR, Herbison GP, Hodaway MD, Hewitt CJ, Flannery EM, Silva PA. The relative risks of sensitivity to grass pollen, house dust mite and cat dander in the development of childhood asthma. Clin Exp Allergy 1989; 19: 419-424.

9. Brooks SM, Baker DB, Gann PH, et al. Cold air challenge and platinum skin reactivity in a platinum refinery: bronchial reactivity precedes skin prick response. Chest 1990; 97: 1401-1407.

10. Venables KM. Low molecular weight chemicals, hypersensitivity, and direct toxicity: the acid anhydrides. $\mathrm{Br} J$ Ind Med 1989; 46: 222-232.

11. Venables KM, Topping MD, Howe W, Luczynska CM, Hawkins R, Newman Taylor AJ. Interaction of smoking and atopy in producing specific IgE antibody against a hapten protein conjugate. BMJ 1985; 290: 201-204.

12. Young RP, Barker RD, Pile KD, Cookson WOCM, Newman Taylor AJ. The association of HLA-DR3 with specific IgE to inhaled acid anhydrides. Am Rev Respir Crit Care Med 1995; 151: 219-221.

13. Barker RD, van Tongeren M, Harris JM, Gardiner K, Venables KM, Newman Taylor AJ. Risk factors for sensitisation and respiratory symptoms among workers exposed to acid anhydrides: a cohort study. Occup Environ Med 1998; 55: 684-691.

14. van Tongeren MJA, Barker RD, Gardiner K, et al. Exposure to acid anhydrides in three resin and one cushioned flooring manufacturing plants. Ann Occup Hyg 1995; 39: 559-571.

15. Yan K, Salome C, Woolcock AJ. Rapid method for the measurement of bronchial responsiveness. Thorax 1983; 38: 760-765.

16. Topping MD, Venables KM, Luczynska CM, Howe W, Newman Taylor AJ. Specificity of the human IgE response to inhaled acid anhydrides. J Allergy Clin Immunol 1986; 77: 834-842.

17. UK Health and Safety Executive. Aromatic carboxylic acid anhydrides in air. Laboratory method using glassfibre/Tenax tube sampling and high performance liquid chromatography. Methods for the determination of hazardous substances, no. 62. Health and Safety Executive. Her Majesty's stationary office, London, 1988.

18. van Tongeren MJA, Barker $\mathrm{RD}$, Gardiner $\mathrm{K}$, et al. Retrospective exposure assessment for a cohort study into respiratory effects of acid anhydrides. Occup Environ Med 1998; 55: 692-696.

19. Maccia CA, Bernstein IL, Emmett EA, Brooks SM. In vitro demonstration of specific IgE in phthalic anhydride hypersensitivity. Am Rev Respir Dis 1976; 113: 701-704.

20. Howe $\mathrm{W}$, Venables KM, Topping MD, et al. Tetrachlorophthalic anhydride asthma: evidence for specific $\mathrm{IgE}$ antibody. J Allergy Clin Immunol 71: 5-11.

21. Zeiss CR, Patterson R, Pruzansky JJ, Miller MM, Rosenberg M, Levitz D. Trimellitic anhydride-induced airway syndromes: Clinical and immunologic studies. $J$ Allergy Clin Immunol 1977; 60: 96-103.

22. Nielsen J, Welinder H, Skerfving S. Allergic airway disease caused by methyltetrahydrophthalic anhydride. Scand J Work Env Health 1989; 15: 154-155.

23. Liss GM, Bernstein D, Genesove L, Roos JO, Lim J. Assessment of risk factors for IgE mediated sensitisation to tetrachlorophthalic anhydride. J Allergy Clin Immunol 1993; 92: 237-247.

24. Nielsen J, Welinder H, Horstmann V, Skerfving S. Allergy to methyltetrahydrophthalic anhydride in epoxy resin workers. Br J Ind Med 1992; 49: 769-775.

25. Renstrom A, Malmberg P, Larsson K, Lasson PH, Sundblad B-M. Allergic sensitisation is associated with increased bronchial responsiveness: a prospective study of allergy to laboratory animals. Eur Respir J 1995; 8: 15141519.

26. Cockcroft DW, Ruffin RE, Dolovich J. Allergen-induced increases in nonallergic bronchial reactivity. Clin Allergy 1977; 7: 503-513.

27. Malo J-L, Cartier A, Ghezzo H, LaFrance M, McCants M, Lehrer SB. Patterns of improvement in spirometry, bronchial hyperresponsiveness, and specific IgE antibody levels after cessation of exposure in occupational asthma caused by snow crab processing. Am Rev Respir Dis 1988; 138: 807-812.

28. Dougla JDM, McSharry C, Blaikie L, Morrow T, Miles S, Franklin D. Occupational asthma caused by automated salmon processing. Lancet 1995; 346: 737-740.

29. Kennedy SM, Burrows B, Vedal S, Enarson D, ChanYeung M. Methacholine responsiveness among working populations. Am Rev Respir Dis 1990; 142: 1377-1383.

30. Dales RE, Hill GB, Spitzer WO. Adult respiratory diseases and tobacco smoke. In: Hirsch A, Goldberg M, Martin J-P, Masse R, eds. Prevention of Respiratory Diseases. 1993; Marcel Dekker, New York, NY, USA, pp. 417-440. 